\title{
Introduction: Undressing Patriarchy and Masculinities to Re-politicise Gender
}

\author{
Jerker Edström, with Abhijit Das and Chris Dolan
}

\begin{abstract}
Much has happened in debates, practice and policy on gender in development since the millennium, when an IDS Bulletin was first published on 'Men, Masculinities and Development'. The present issue picks up on several developments in the interim, by drawing contributions from participants at a recent international symposium, 'Undressing Patriarchy'. It explores the shifting field of men and masculinities in development and how the field's often conflicted engagements with the feminist project of redressing gender inequalities might be radicalised through a deeper analysis of patriarchy and our relationship to it, as well as by linking it to other struggles for sexual and human rights, or social justice. The introduction sets the context and gives a brief background to our rationale for 'undressing patriarchy' as our chosen approach. The authors then comment on the contributions to each section of the IDS Bulletin, and conclude with an outline of some future priorities.
\end{abstract}

\section{Introduction}

As the international community looks beyond the current Millennium Development Goals for 2015, towards some new and more Sustainable Development Goals, we take up the issue of how men and masculinities feature in debates, practice and policy on gender in development. Much has happened since the millennium, when Cornwall and White presented a first IDS Bulletin on 'Men, Masculinities and Development' (2000), exploring polices, politics and practice in how masculinities research and action had been finding its way onto the lexicon and agendas of gender and development (GAD) at the time. The present issue picks up on several developments in the interim, by drawing contributions from participants at a recent international symposium, 'Undressing Patriarchy: Redressing Inequalities' (Hawkins et al. 2013). We explore the shifting field of men and masculinities in development and how men's often conflicted engagements with the feminist project of redressing gender inequalities might be deepened and radicalised, through a deeper analysis of patriarchy and our relationship to it, by also linking it to other struggles for sexual and human rights, or social justice. In this introduction we start by setting the context and giving a brief background to our rationale for 'undressing patriarchy' as our chosen approach and as the logic behind the structure of this IDS Bulletin. We then comment on the contributions and conclude with a brief section on some thoughts and priorities for the future.

With roots in fields such as social psychology and sex role theories from the 1960 s and 1970 s, research by social scientists in the 1980 s began to focus on the cultural production of masculinities and different models of 'manhood', beginning to question notions of any essential male power (e.g. Kimmel 1987; Brod 1987; Kimmel and Messner 1989). The emerging field of 'men and masculinities' started to make new connections around masculinity and men in relation to a set of social issues and concerns, such as class, racism and homophobia. An early focus in this work was on male inner lives, identities and inter-relations (e.g. Bly 1992; Kimmel 1987) and other strands also included debates on the more institutional or structural dimensions of men's power (e.g. Back 1994; Brittan 1989; Hearn 1996; Seidler 1997; Willis 1981) and focusing also on social inequalities and intersections of gender 
with class and race. This turn towards masculinities also opened up a political promise, by challenging the static binaries of earlier sex role theory.

The deeper relationship between gender and power also began to be explored differently by focusing on how certain ways of 'being a man' are privileged within different cultural settings and exposing the reality of subordinate or 'subaltern' variants of masculinities (Carrigan et al. 1985), particularly associated with R.W. Connell's (1995) book Masculinities. In revealing the earlier 'unmarked male', the field has helped to open up the possibilities of disrupting patriarchal knowledge-power systems, also making new questions easier to frame, for example on sexuality and intimacy, identity and exclusion, as well as violence and trauma, in men's lives.

Related to this, a wealth of research contributed to the increasing dislocation of 'masculinities' from 'men' (e.g. Cornwall and Lindisfarne 1994) and the development of the concept of 'hegemonic masculinity', which gained much traction in terms of explaining the role of masculinity in oppressive gender orders and relations, including its oppression of subordinate men (Connell and Messerschmidt 2005).

Linked to these developments, as well as to broader changes in debates about women in development (WID) progressing to similarly diverse and relational feminist understandings of GAD, there has been a significant expansion of programming and policy on men and boys within gender and development. With much energy and impetus from women's struggles for reproductive rights, much of this work focused initially on sexual and reproductive health. From the 1994 Cairo International Conference on Population and Development (ICPD) and the Platform for Action outlined at the 1995 Fourth World Conference on Women in Beijing through to the 2000 World AIDS Day campaign on the theme 'Men Make a Difference', or the Declaration of Commitment of the 26th UN General Assembly Special Session (UNGASS) on HIV/AIDS in 2001, men's roles, potential contributions and responsibilities became increasingly named and visible. Subsequently, an increase in attention to gender-based violence has also helped expand violence prevention work with men and boys, with a predominant focus on violence within heterosexual relationships.
By the late noughties some thinkers and activists in the field were taking stock of progress and constraints and came together in an event in Dakar, Senegal (Esplen and Greig 2008), from which new insights were published in the book Men and Development: Politicizing Masculinities (Cornwall et al. 2011). Some of the areas of progress noted were that: men can change and are changing (since masculinities are socially constructed they can be reconstructed); men's resistance to hegemonic forms of masculinity is possible and can be motivated by highlighting the costs of masculinity for men; much work with men and boys treads carefully with a desire not to 'turn men off' or to blame them individually for the injustices and harms of patriarchy; and that 'engaging men' in gender equality struggles had come to be about the need to transform masculinity by changing cultural or social norms that guide men's behaviour. The editors noted that 'equally striking, however, are some of the silences and absences in this work' (ibid.: 5). Some of these silences included that: rather little was being said in this discourse about men's plural sexualities and that work with men who have sex with men (MSM) had developed almost in parallel with more mainstream work with men and boys; the focus on norms and behaviour in approaches to gender-based violence had steered away from deeper discussions of the institutionalised nature of violence and what would really be required to address that; work on fatherhood had often said less about other domestic issues, like a more equal division of labour in the home, and paid less attention to deeper political and economic inequalities facing those subordinated in prevailing gender orders. These silences may, in part, explain some feminists' ambivalence about such debates on masculinities and work engaging men and boys. The editors flagged that 'ensuring that this engagement gets to grips with gender and its structuring of inequalities is critical if the promise of masculinities work with men for greater gender justice is to be realised' (ibid.: 6).

\section{Undressing patriarchy?}

So, can 'patriarchy' itself then help us 'get to grips with gender and its' structuring of inequalities' (ibid.6)? Whilst the word originates in ancient Greece, where it meant 'rule of fathers', the actual concept of patriarchy was brought into use in Europe during the mid seventeenth century, in order to shore up feudal systems, which operated 
on principles of patrilineal descent and inheritance. In more recent times, both Freidrich Engels (1884) and Max Weber (1922) argued that family-centred patriarchy was also the underlying model for a more general dominance of men in society and the concept gradually became more used in this broader sense of the rule of men in society. Twentieth-century feminist thought further popularised the term and emphasised patriarchy's associated systematic oppression and subordination of women (e.g. Pateman 1988).

However, with the decline of grand structural social theories in an era of neoliberalism (in political economy and development) and poststructuralism (in the social sciences), 'patriarchy' as a conceptual tool somewhat receded from view over the nineties and noughties. Nevertheless, recently patriarchy seems to be enjoying something of a revival and reconsideration in debates around masculinity and gender equality. Whilst patriarchy involves aspects of male supremacy, male privilege and the subordination of women, it is not the same 'thing', nor reducible to either one of those. Rather, we understand the notion to centre on some form of power system/s where gendered hierarchies of power relations are structured through some form/s of male (or masculine) lines or logic, which tends to result in male privilege - particularly the privileging of some men - and the subordination of all others, albeit to varying degrees.

So, why pick patriarchy rather than some other concept? The rationale for choosing this framing has included a range of reasons, such as:

frustrations over current divergent trends under the broad rubric of 'gender'; concerns with the abstract and de-gendered (or, gender-obscured) methodological individualism of the increasingly contested 'neoliberal consensus' or 'neoliberal hegemony'; and, a widening unease at the often homogenising and superficial reductions of complex issues of gender justice, which tend to gloss over North-South contradictions or dynamics at the intersections of gender with race, class, caste, nation, sexuality or disability. For example, anti-feminist backlashes and a more general backsliding on progress in gender equality have led some to warn of feminisms in crisis and a fragmentation of the field, with a neoliberal co-option of key terms and concepts in the service of global capitalist, religious or other geopolitical agendas, which otherwise deny or downplay any redressing of the subordination of women as secondary (Batliwala and Dhanraj 2004; Cornwall et al. 2007; Fraser 2009).

For these and other reasons, the international symposium 'Undressing Patriarchy' was convened to broaden the debate, inviting new perspectives and connecting the men and masculinities debate more concretely with conversations and activism within feminism, sexual rights and broader social justice movements, in order to more deeply explore the connections between the resilience of patriarchy and other evolving systems which constrain or facilitate increasing equality for all genders. Some 40 participants came together for 'Undressing Patriarchy' in Brighton, 9-12 September 2013. Early drafts for the great majority of articles in this issue were submitted for this unlikely encounter of unusual suspects engaging in unconventional dialogues, and at least one of the authors for each contribution participated in the symposium. This IDS Bulletin focuses primarily on those perspectives which were most directly speaking to the discourse on and debates on 'men and masculinities'. Other excellent contributions to the symposium may be developed for other outlets in the future, but in the meantime we also encourage readers to explore the report of the symposium itself (Hawkins et al. 2013). Another limitation with this IDS Bulletin is the pale fact that the last two sections are written almost entirely by white men from Northern countries. Contributions from eminent feminist women writers and activists were requested for these sections too, but for an unfortunate combination of reasons these could not be generated on time (although there was a strong expressed desire to join in). Nevertheless, we hope that the positive contributions from pieces in this issue will outweigh any negative impact of this imbalance, and we publish this in the spirit of continuing a deepening conversation between fields and perspectives.

The IDS Bulletin is structured to take us through a number of turns, intentionally unsettling at first, but ultimately directed. The first section provides a set of contrasting and diverse perspectives on masculinities and gender in contextualised and shifting patriarchal orders, in order to help us both update our understandings of men and patriarchy in development, and to challenge some of our preconceptions. In turn, the second section explores evolving work with 
men and boys, in order to highlight areas of progress and constraints. This includes some local experiences of action, strategies and alliances which take a relational and increasingly pro-feminist approach. In the third section, we aim to raise our gaze 'upstream' onto the level of international policy discourse and framings, which influence much national and local action on gender, where contributions also provide suggested directions for the future. The final section attempts a more reflective and theorising turn, by proffering personal-political reflections on theory and politics of the masculinities field's encounter with feminism and social justice, within the development context.

\section{Perspectives on men, masculinities and shifting patriarchal orders}

In the first and most substantive part of this $I D S$ Bulletin, we present five articles describing diverse realities, changes and shifting constraints for men, women and patriarchy in their daily lives. The contexts differ across many countries and the articles touch on issues of change in livelihoods and social status dynamics, intersectionality, homophobia as well as issues around sex and work, in sometimes rather unexpected ways.

In the first article, John Spall takes us straight into Africa with his article "Money has More Weight than the Man": Masculinities in the Marriages of Angolan War Veterans'. Based on his year of participant observation and interviews in Huambo, tracing war veterans' life histories and personal post-conflict struggles to turn a profit in a war-torn economy, where 'masculine status and authority had come to depend crucially on monetary income', Spall analyses these men's reactions to the erosion of earlier relative certainties of patriarchal orders from pre-war society as well as in military life, alongside their new anxieties.

In the second piece, 'Poor Man's Patriarchy: Gender Roles and Global Crises', Naomi Hossain and Alexandra Kelbert throw the net a little wider to illustrate an increasingly common situation of men's 'traditional' expectations of control and patriarchal dividends becoming undermined, more from global economic forces and shocks than from local or regional breaks in peace and conflict. Based on research on experiences of food price volatility in ten countries during 2012, they argue that recent global economic shocks have created a 'poor man's patriarchy - a washed-out version of ancient male privileges, but yoked to responsibilities poor men can rarely meet', whilst old norms geared towards keeping women at home, in unpaid care roles, have also become eroded as paid work is an increasing ambition and a reality for women. The authors also argue that 'in this destabilising of old gender roles, there may be some emancipatory potential' and that current realities may open up new spaces for new forms of coalitions.

So, if there are new opportunities for men to engage in reforming gender orders, is it happening and, if so, how easy is it? The third contribution in this issue asks some of these questions; 'Are Masculinities Changing? Ethnographic Exploration of a Gender Intervention with Men in Rural Maharashtra, India'. Based on an ethnographic study of a cluster of different villages, Ahonaa Roy and Abhijit Das consider the relative success and constraints of gender equality programmes in different sets of villages, which have been implemented on the basis of the ideologies and principles of the movement MASVAW (Men's Action for Stopping Violence Against Women). On the one hand, they describe how men in a majority of the villages studied engage positively in understanding violence and discrimination against women, including in taking action to promote gender equality - at home, at work and/or in education. On the other, whilst exploring the pehalwaani wrestling culture in some villages, the authors reveal a different aspect of masculinity and masculine embodiment, which may explain where MASVAW ideologies fail to take root and which becomes an impediment to bringing new practices of gender equality.

In a fascinating piece on 'Homophobia and Patriarchy in Nicaragua: A Few Ideas to Start a Debate', Patrick Welsh takes us through a thoughtful analysis of contradictory trends and dynamics in relation to same-sex sexual relations, homophobia and patriarchy in Nicaragua. He starts by describing a type of submissive-dominant (or, 'cochón-cochonero') paradigm of fairly 'traditional' homosexual relationships, which he then contrasts with more recent gay - or global lesbian, gay, bisexual, transgender/transexual 
and intersexed (LGBTI) - identities, increasingly emerging in urban centres in particular, but coexisting with the older model. Intriguingly, Welsh argues that despite some 30 or more LGBTI groups having been established in the country, patriarchy is proving resilient, co-opting and adaptive. He points to a balkanisation amongst local LGBTI movements arising from personal and inter-organisational tensions rooted in particular styles of leadership amongst some gay men, which themselves reproduce patriarchal practices. Whilst significant advances have been achieved (on a global scale), Welsh argues that this does not necessarily mean 'that the intensely andocentric character of patriarchy itself has been significantly challenged or altered... For many gay men, perhaps, it simply translates into being able to enjoy the benefits of patriarchy (some at least...) on an "equal basis"...' He goes on to argue that this newfound inclusion might effectively represent a broader move to perpetuate patriarchy itself. In the struggle for equal rights for all, then, he concludes that 'the models and dynamics of patriarchal power itself and how they manifest themselves within LGBT organisations, families and relations must also be addressed... and undressed'.

In a provocative contribution - again from India Meena Saraswathi Seshu and Aarthi Pai propose that 'Sex Work Undresses Patriarchy with Every Trick!'. What? Surely most gender and development discourse repeatedly (if rhetorically) asks us 'is prostitution not the epitome of patriarchy?'. Ironically, even if understood at a very essentialist level, this belief is clearly congruent to the patriarchal notion of feminine sexuality that needs to be 'protected and preserved' from illegitimate male attention. Based on a fascinating dialogue between collectivised sex workers in the Sangli district of Maharashtra with collectivised rural women not in sex work, Seshu and Pai show how many women in sex work feel that the freedom they have carved out from both male and societal oppression cannot be found in the lifestyles available in the male-centred systems outside of dhandha (the 'business'). They also show how many other rural women suffer far greater degrees of patriarchal oppression and regulation. However, sex workers' attempts at self-expression often get dismissed as cases of 'individual defiance' and often result in humiliation. The authors conclude that feminists have often failed to engage with such women's perspectives and that 'moral and ideological frameworks have successfully managed to marginalise and ignore the contribution women in sex work have made to understand the lives of women who live outside accepted societal norms'.

\section{Evolving work with men and boys}

Turning more directly to actual work which is being done with men and boys on issues of masculinities and gender equality as it plays out in different spheres of life, in the second section three articles are presented, from the HIV response in Africa, to experiences from working with men on violence and gender equality in Kenya and India.

Tim Shand and colleagues, in 'The HIV Blind Spot: Men and HIV Testing, Treatment and Care in Sub-Saharan Africa', take a panoramic view of the state of work on men and HIV testing, treatment and care work in sub-Saharan Africa. Evidence shows that men are significantly underrepresented in HIV testing and treatment services. Within the sub-Saharan Africa region, national policies and responses have insufficient focus on encouraging men to test for HIV and access to treatment and support, or on the disproportionate burden of HIV care which falls on women. Being bad for men's health as well as placing major and unnecessary burdens on women and health systems, they argue that this blind spot must be urgently remedied.

Furthermore, they argue that such remedial programming and policies 'should happen within the context of addressing power differentials between men and women at all levels'. This, they argue, would include 'challenging the broader patriarchal power structures in which gender plays out, such as the assumption that care work is "women's work" ... and the rigidity of gender norms that encourage men to participate in risktaking behaviours...'

\section{Writing about 'Male Engagement in}

Deconstructing Institutional Violence in Kenya', Phil Erick Otieno describes his understanding of the context of violence as a power issue and the need to understand its root causes, as well as its manifestations, through relations of power in all spheres of life. In addition to the importance of changing norms and attitudes, Otieno stresses the need for influencing policy and practice in both public and private institutions, through a variety of contextually specific pathways to 
change. Otieno draws out the sensitivities around male engagement at community level, describing how whilst many men are ready to become engaged in working for gender equality, they often require a secure and non-threatening platform in order to create the space required for non-violent reflections and deliberations on gender issues and inequities in their personal lives, communities and work. Borrowing a methodology of consciousness-raising from the feminist movement, these safe spaces have proved to be helpful in enabling men to reflect more deeply, both on the rationales for a violence-free society where females and males are valued equally and on the need to interrogate the structural dimensions of violence that impedes the attainment of that goal.

\section{In their article on 'Changing Men: Challenging} Stereotypes. Reflections on Working with Men on Gender Issues in India', Abhijit Das and Satish K. Singh reflect on their long experience of working with men at the community level in different parts of India. Having started with addressing domestic and inter-personal violence, the work is beginning to also address broader power structures, control and autonomy within the context of deep-seated cultural beliefs and practices, challenging and changing the roles of men both within their homes and outside, with a focus on different institutions. In reviewing the lessons from their practice the authors propose a set of precepts, in a seven-point theory of change. In concluding, they discuss some of the challenges and predicaments in continuing this work within the current development paradigm, particularly in terms of taking the work to a higher-level audience and debates at national and international policy levels. Acknowledging some anxiety and apprehension, they ask, 'Will it be possible to retain the reflective, dialogic and empowering processes that we tried to nurture? Will public functionaries be able to emerge as role model-activists...? Will men on a large scale be able to overcome the pre-existing social script...?'

\section{Development policy and men and boys}

This section takes us through at least three proposed steps for moving forward:

i challenging the current one-sided, binary and essentialist constructions of gender inequalities, which not only make men invisible, but themselves become oppressive; ii crafting policy on men and gender to orient our gaze and action to actually equalise caring roles and work across genders in both public and domestic spheres; and

iii the need to integrate and anchor the engagement of men and masculinities in future development goals and directions for these to take a more structural direction.

In 'Has Patriarchy been Stealing the Feminists' Clothes? Conflict-related Sexual Violence and UN Security Council Resolutions', Chris Dolan takes us to the sphere of international policy instruments and how gender has come to be codified in essentialist terms focusing almost entirely (and sometimes literally by definition) on women's vulnerability and victimhood, to the exclusion of men as anything but presumed perpetrators of violence against women, or as ineffectual would-be protectors. He critically scrutinises the framings of conflict-related sexual violence in past UN Security Council Resolutions (UNSCR), which he argues have made invisible the reality of male victimisation and vulnerability to sexual and other violence. However, pointing to two recent events - the declaration on preventing sexual violence in conflict adopted by G8 foreign ministers on 11 April 2013 in London and the UNSCR resolution 2106, adopted just two months later, on 24 June in New York - he argues that these may herald the 'beginning of the end' of a particularly one-sided, hegemonic and oppressive paradigm of gender analysis and response which has dominated international policy and action for several decades and which itself rests on - and thus shores up - patriarchal assumptions and relations.

In the article 'A Radical Agenda for Men's Caregiving', Gary Barker argues for a new global development goal of men and boys taking on 50 per cent of unpaid care work across the world. In a pointed double meaning he boldly proposes that for men and boys to 'do gender justice' and to achieve better and fuller lives (and for women and girls to realise their full political, social and professional potentials) requires a radical redistribution of care work, placing the politics of men's caregiving at the front line of any true revolution for gender equality. Barker points to significant changes in the social imagination, linked to generational shifts from new generations experiencing greater gender equality and young 
men 'who have increasingly seen their mothers and other women... working outside the home and... in positions of leadership'. Furthermore, he cites evidence from the International Men and Gender Equality Survey (IMAGES) that young, urban men with secondary education are typically more accepting of gender equality, as well as being more likely to practise equitable behaviours in their daily lives. In the general context of increasing urbanisation and improvements in levels of boys' and girls' education, he challenges us to take this as a serious - if ambitious - proposition.

Paul Dover closes this section on policy by providing a development cooperation agencyperspective in 'Gender and Development Cooperation: Scaling up Work with Men and Boys'. As development cooperation is a major source of sustenance for work on gender equality and since achieving gender equality goals will need stronger engagement from men, Dover reflects on the background, context and some current international policy trends in development cooperation work on gender with men and boys. He concludes with identifying some challenges and opportunities for the future, stressing the need to integrate the issues of men and masculinities in upcoming post-2015 policy formulations and to prioritise more structural approaches to the engagement of men and boys in gender equality work.

\section{Theorising patriarchy and the politics of the 'men and boys' encounter with feminism}

The final part of this IDS Bulletin aims to provide a set of more personal, reflective and theoretical perspectives, looking into what it means to make the personal political in engaging men, as a man, grappling with the thorny task of reading 'homosocial' relations between men in the context of intersections of multiple forms of inequalities, as well as proposing ways of deconstructing or undressing patriarchy, which engages with feminist insights, holding us to account for how we engage personally in social systems of gendered power.

Marc Peters starts off this 'searching' part of the IDS Bulletin by 'Reflecting on the Oppressor in the Mirror'. Acknowledging the feeling of drain and dread a 'straight white man from America' (yes, a privileged man, on virtually all scales) feels in talking about race, gender, violence, societal discrimination, power and oppression, Peters admits he would rather stay silent for a while. However, he points out that even the option of silence is part of his white male privilege, and therefore goes on to reflect on the built-in benefits that turning a blind eye to social injustice proffers. He highlights how systemic patriarchal benefits confer abilities as well as incentives to ignore the unprivileged, and how this contributes to the phenomenon that even those who recognise the systems of oppression in place (and who believe in a fairer and more just world) can lack the sense of urgency needed to bring about change. Critically exploring his own attitudes to other men in his past - including having taken the option of disengaging with non-progressive 'oppressors' - he concludes by taking a leaf out of Nelson Mandela's philosophy and urges us to engage with even the powerful, on the assumption that we all have some shared humanity.

In the article 'Towards an Intersectional Approach to Patriarchy: Male Homosociality in an American Context', Frank G. Karioris begins an exploration of how male homosociality might be analysed, by using a multidimensional and intersectional lens. Illustrating the discussion through current performances and ideals of masculinity amongst American men, he proposes a way of understanding patriarchy as a starting point for theorising about the various factors which impact on the nature of men's homosocial relations, as well as the role these can play in perpetuating or undermining larger social structures which shape existing inequalities. To do this, Karioris looks at various elements of these relations, related to power, silence and intimacy and he argues that notions 'of combative masculinity and the self-made man promulgate an individualised rationalising away of systemic inequality'. He suggests that we must also start to explore 'the version of masculinity and relations that exists at the margins of this, which are bending the singular vision of these relations' and that viewing men's homosocial relations in such terms can allow us to (i) apply an individual critique whilst maintaining a critical focus on the larger structures connecting power and masculinity through patriarchy, as well as to (ii) further explore the politicised multidimensional and intersectional aspects of oppression. He argues that men's homosocial relations are created by 'structural and phenomenological directives that determine [their] shape, scope, and form' and which also 
'seek to eliminate alternatives'. To the extent that patriarchy is 'built on men's oppression of women', we are encouraged also 'to question the dictates which it puts upon men'.

Jerker Edström ends the final section with an exploratory attempt to construct a possible framework for undressing patriarchy in 'The Male Order Development Encounter'. He peels off four dimensions to patriarchy - four 'Ms' from the more familiar representational, redistributive and ideological/political dimensions to a fourth epistemological dimension, illustrating how these can be applied to the treatment of men and masculinities in development. The first three are 'male centredness', 'male privilege' and 'male supremacy', but the fourth dimension is perhaps least obvious, or developed. Here, Edström proposes to build a concept of 'male order', in an epistemological dimension which aims at responding to some feminist thinkers' call to unearth the deep structures of constraint to gender equality. Combining ideas of knowledgepower and an inversion of hegemonic masculinity to 'the masculinity of hegemony', he believes male order may help to explain the very binary syntax of patriarchal systems of knowledge, focused on control, order, linearity and expansion. Within the development industry, Edström illustrates the concept with: trends in 'the results agenda', the privileging of certain kinds of 'scientific' knowledge (such as the tyrannical 'gold-standard' of Randomised Controlled Trials) and linear output-driven management frameworks, set against a push-back from civil society and critical academics. Without greater reflective political engagement and selfawareness, the male engagement field may remain particularly susceptible to internalising such male-ordered patriarchal logics.

\section{Concluding directions forward}

Building on the significant progress in work on masculinities in gender and development and taking account of efforts and certain moments of regrouping for making the work political, as editors and contributors, we are here attempting two feats: on the one hand, we want to update our readers on the changing state of the field and, on the other hand, we want to better connect these debates to insights from feminism, sexual rights and social justice, through a methodology of 'undressing patriarchy', as a way to focus on the underlying drivers of gender equality, rather than getting stuck in a generalised fallacy casting all men as patriarchs.

By contrasting perspectives on the changing realities of men, women and masculinities within shifting power orders, across many countries and voices, we learn about changes in livelihoods and social status dynamics, homophobia and gendered dynamics around sex and work, in ways which cast doubt on more familiar narratives and development sector framings. By exploring some of the front line work being done with men and boys on issues of gender equality, we learn about remaining 'blind spots' around men's own needs, about how consciousness-raising and a focus on structural or institutional drivers and obstacles can help with deepening men's engagement, and about some of the challenges in this work yet to be overcome, particularly as we move upstream towards 'policy'.

Exploring development policy and discourse on men and boys in relation to gender equality, we are here presented with a challenging perspective on familiar binary and essentialist constructions of gender inequalities, which not only make men invisible, but themselves become oppressive and in some ways even patriarchal. We are also challenged to seriously consider advocating for new development policy goals to explicitly include men and towards actually valuing and equalising caring roles and work across both genders in public as well as domestic spheres. On a positive note, we also learn that some donor representatives are articulating a need to integrate and anchor the engagement of men and boys in future development goals, as well as making suggestions for how these can take a more structural direction than has been the case to date.

Pointing towards the need for further deepening our analysis of patriarchal power and oppression as systemic and dynamic - but amenable to change - the last few articles highlight possible pathways for greater engagement across perspectives on social justice, with greater reflexivity on our roles and positions within the power systems we are critiquing. Ultimately, an important part of this comes down to not taking patriarchy personally, but more intelligently making it political as well as deeply personal in our lives and work. 
The findings and conclusions of this IDS Bulletin are many and, in addition to specific recommendations for practice, politics and policy, there are clear directions flagged for deepening research and debates. The methodology of dialogues across contrasting perspectives is challenging but also revealing, fun and ultimately, hopefully liberating. There seems to be a growing interest and demand for developing new research on patriarchy and 'men in power' across different sectors and settings. The power of film-making and alternative creative media for communicating lessons, perspectives and ideas has been raised in this process as something to explore through developing South-South exchanges, or 'travelling film caravans'. There is a need for greater exchange of lessons - from working across generations to exploring the linkages and tensions between men's groups and

\section{References}

Back, L. (1994) 'The "White Negro" Revisited: Race and Masculinities in South London', in A. Cornwall and N. Lindisfarne (eds), Dislocating Masculinity: Comparative Ethnographies, London: Routledge

Batliwala, S. and Dhanraj, D. (2004) 'Gender Myths that Instrumentalise Women: A View from the Indian Frontline', IDS Bulletin 35.4: $11-18$

Bly, R. (1992) Iron John: A Book about Men, New York: Random House

Brittan, A. (1989) Masculinity and Power, Oxford: Blackwell

Brod, H. (ed.) (1987) The Making of Masculinities: The New Men's Studies, Boston: Allen and Unwin Carrigan, T.; Connell, R.W. and Lee, J. (1985) 'Towards a New Sociology of Masculinity', Theory and Society 14.5: 551-600

Connell, R.W. (1995, 2nd edition 2005) Masculinities, Cambridge: Polity, http://books.google.co.uk/ books?id $=$ YuR2uFxxvPoC\&printsec $=$ frontcover\&source $=$ gbs_ge_summary_ $\mathrm{r} \& \mathrm{cad}=0 \#_{\mathrm{v}}=$ onepage $\& \mathrm{q} \& \overline{\mathrm{f}}=$ false $($ accessed 2 December 2013)

Connell, R.W. and Messerschmidt, J. (2005) 'Hegemonic Masculinity: Rethinking the Concept', Gender and Society 19.6: 829-59 Cornwall, A. and Lindisfarne, N. (eds) (1994), Dislocating Masculinity: Comparative Ethnographies, London: Routledge Cornwall, A. and White, S. (eds) (2000) 'Men, Masculinities and Development: Politics, Policies and Practice', IDS Bulletin 31.2 women's organisations. It has also become clear that deeper exploration of the intersections between patriarchy and disability is an area in need of much further development. More enabling theories of change and conceptual frameworks along with practical methodologies for consciousness-raising and facilitating dialogues across different constituencies are also all in need of further development. The list will go on, but we hope this IDS Bulletin will trigger new thoughts and contribute significantly to an ongoing conversation.

We can dress down men all we like, but we would be better off recognising that gender inequality is not just the economy, geopolitics or some innate 'sex differences'. We need to undress patriarchy together, whilst holding ourselves and each other accountable in the process.

Cornwall, A.; Edström, J. and Greig, A. (2011)

'Introduction: Politicizing Masculinities', in Andrea Cornwall, Jerker Edström and Alan Greig (eds), Men and Development: Politicizing Masculinities, London: Zed Books

Cornwall, A.; Harrison, E. and Whitehead, A. (2007) 'Gender Myths and Feminist Fables: The Struggle for Interpretive Power in Gender and Development', Development and Change 38.1: 1-20

Engels, F. (1884) Der Ursprung der Familie, des Privateigenthums und des Staats [available in English (1972) Origin of the Family, Private Property and the State, Pathfinder Press]

Esplen, E. and Greig, A.; with Cornwall, A. and Edström, J. (2008) Politicising Masculinities: Beyond the Personal, report of an International Symposium held in Dakar, October 2007, Brighton: IDS

Fraser, N. (2009) 'Feminism, Capitalism and the Cunning of History', New Left Review 56: 97-117

Hawkins, K.; with Bisht, P.; Kelbert, A.; Maldonado Pacheco, C.; Nesbit-Ahmed, Z. and Edström, J. (2013) Undressing Patriarchy: Redressing Inequalities, report of an International Symposium, 9-12 September 2013, Brighton: IDS

Hearn, J. (1996) 'A Critique of the Concept of Masculinity/Masculinities', in Mairtin Mac An Ghaill (ed.), Understanding Masculinities, Buckingham PA: Open University Press Kimmel, M. (1987) 'Rethinking "Masculinity": New Directions in Research', in M. Kimmel 
(ed.), Changing Men: New Directions in Research on Men and Masculinity, Boston: Sage

Kimmel, M. and Messner, M. (eds) (1989) Men's Lives, Boston MA: Allyn and Bacon

Pateman, C. (1988) The Sexual Contract, Stanford: Stanford University Press

Seidler, V. (1997) Man Enough: Embodying Masculinities, London and Thousand Oaks CA: Sage
Weber, M. (1922) Wirtschaft und Gesellschaft: Grundriß der verstehenden Soziologie [published in English (1978) Economy and Society, Berkeley CA: University of California Press]

Willis, P. (1981) Learning to Labour: How Working Class Kids get Working Class Jobs, New York: Columbia University Press 